\title{
Cellular mechanisms of bone remodeling
}

\author{
Erik Fink Eriksen
}

Published online: 29 December 2010

(C) The Author(s) 2010. This article is published with open access at Springerlink.com

\begin{abstract}
Bone remodeling is a tightly regulated process securing repair of microdamage (targeted remodeling) and replacement of old bone with new bone through sequential osteoclastic resorption and osteoblastic bone formation. The rate of remodeling is regulated by a wide variety of calcitropic hormones (PTH, thyroid hormone, sex steroids etc.). In recent years we have come to appreciate that bone remodeling proceeds in a specialized vascular structure,the Bone Remodeling Compartment (BRC). The outer lining of this compartment is made up of flattened cells, displaying all the characteristics of lining cells in bone including expression of OPG and RANKL. Reduced bone turnover leads to a decrease in the number of BRCs, while increased turnover causes an increase in the number of BRCs. The secretion of regulatory factors inside a confined space separated from the bone marrow would facilitate local regulation of the remodeling process without interference from growth factors secreted by blood cells in the marrow space. The BRC also creates an environment where cells inside the structure are exposed to denuded bone, which may enable direct cellular interactions with integrins and other matrix factors known to regulate osteoclast/ osteoblast activity. However, the denuded bone surface inside the BRC also constitutes an ideal environment for the seeding of bone metastases, known to have high affinity for bone matrix. Circulating osteoclast- and osteoblast precursor cells have been demonstrated in peripheral blood. The dominant pathway regulating osteoclast recruitment is the RANKL/OPG system, while many different factors
\end{abstract}

E. F. Eriksen $(\bowtie)$

Department Of Clinical Endocrinology, Oslo University Hospital,

Aker,

Trondheimsveien 235,

0514 Oslo, Norway

e-mail: e.f.eriksen@medisin.uio.no
(RUNX, Osterix) are involved in osteoblast differentiation. Both pathways are modulated by calcitropic hormones.

Keywords Osteoblasts · Osteoclasts · Lining cells · Growth factors · Cytokines · Bone remodeling · Osteoporosis · Bone remodeling compartment

\section{Introduction}

Bone histomorphometry has given us great insights into bone physiology and bone remodeling in particular. Histomorphometric indices obtained using tetracycline double labeling techniques are unique, because they contrary to DXA and bone markers reflect cellular activity of osteoclasts and osteoblasts using the incorporation of a time marker, namely spaced administration of an agent (tetracycline) reflecting ongoing active bone formation. The study of bone remodeling originated with the classical works of Harold Frost 40 years ago [1] and our ever expanding understanding of this process is the basis for the development of highly effective treatments for osteoporosis, that we have seen over the last 20 years.

\section{The bone remodeling cycle}

Although macroscopically the skeleton seems to be a static organ, it is an extremely dynamic tissue at the microscopic level. The ability of bone to sustain the tremendous loads placed on it in everyday life depends on, constant repair of mechanical microdamage that develops both in cancellous bone - the "spongy" bone present in the vertebrae, pelvis, and ends (metaphyses) of long bones - and in cortical bone - the compact bone present in the shafts (diaphyses) of the long bones and surrounding cancellous bone as a thin layer in the 
vertebrae and pelvis. Bone remodeling is based on the concerted action of resorptive and formative cell populations in order to replace old bone with new bone and thus secure the integrity of the skeleton. This sequence has to be tightly regulated by both local and systemic factors, because significant deviations from a neutral balance between resorption and formation would mean severe accelerated bone loss or bone gains with possible disastrous consequences in terms of increased fracture risk or compression syndromes.

Bone remodeling takes place in what Frost termed the Basic Multicellular Unit (BMU), which comprises the osteoclasts, osteoblasts, and osteocytes within the boneremodeling cavity (Fig. 1). In cancellous bone remodeling occurs on the surface of trabeculae and lasts about 200 days in normal bone. The remodeling cycle can be as short as 100 days in thyrotoxicosis and primary hyperparathyroidism and exceed 1,000 days in low turnover states like Myxedema and after bisphosphonate treatment [2]. Remodeling is initiated by osteoclastic resorption, which erodes a resorption lacuna, the depth of which varies between 60 in young individuals and $40 \mu \mathrm{m}$ in older individuals. The resorption period has a median duration of 30-40 days and is followed by bone formation over a period of 150 days (Fig. 1) [3, 4]. In normal bone the result of the remodeling cycle is complete refilling of the resorption lacuna with new bone. In disease states like osteoporosis, the main defect is that the osteoblast is unable to refill the resorption lacuna leading to a net loss of bone with each remodeling event

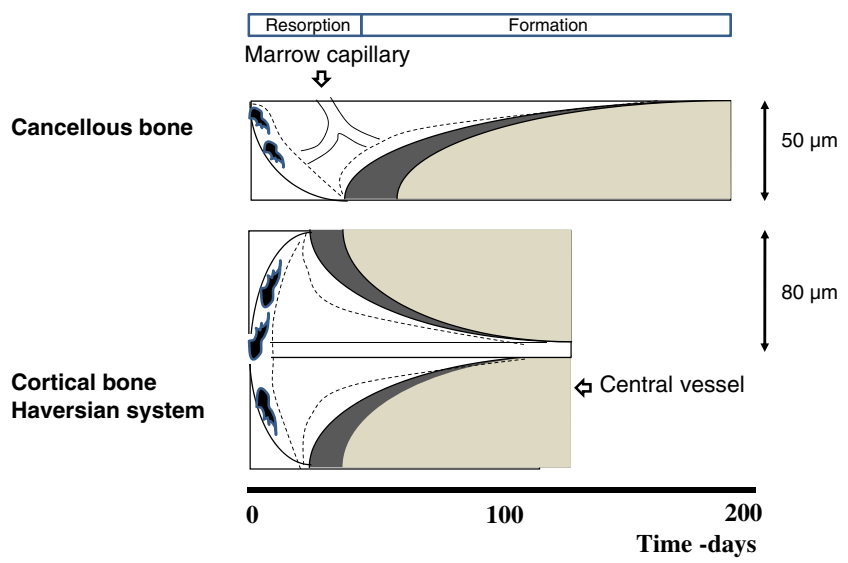

Fig. 1 Schematic representation of Bone Multicellular Units (BMUs) in cancellous and cortical bone. Broken lines denote the outer limit of Bone Remodeling Compartment associated with the resorptive and formative sites of the BMU. The mean thickness of the structure in cancellous bone is $50 \mu \mathrm{m}$ and $80 \mu \mathrm{m}$ in cortical bone equivalent to a mean Haversian system diameter of $160 \mu \mathrm{m}$. The Blood supply for the $\mathrm{BRCs}$ is provided by capillaries either coming from the marrow space as is the case for cancellous BMUs or from the central vessel of Haversian systems in cortical bone. The duration of the remodeling sequence is somewhat longer in cancellous than in cortical bone. The position of marrow cappillaries is hypothetical, as the exact distribution is poorly elucidated
[5]. In cortical bone remodeling proceeds in tunnels with osteoclasts forming "cutting cones" removing damaged bone followed by refilling by osteoblasts in the "closing cone" occurring behind the osteoclasts [6]. In normal bone the duration of the remodeling cycle in cortical is shorter than in cancellous bone with a median of 120 days [6]. The total surface of cancellous bone is completely remodeled over a period of 2 years.

Contrary to remodeling sites in cancellous bone, which are close to red marrow, known to contain osteoprogenitor cells [7], remodeling sites in cortical bone are distant from red marrow. Therefore, it was assumed that the mechanisms of bone remodeling were different in cancellous versus cortical bone, i.e. that the cells needed for bone remodeling in cancellous bone traveled directly from the red marrow to bone surfaces in cancellous bone, while cells reached cortical remodeling sites bone via the vasculature [8].

\subsection{Osteoblast differentiation}

Osteoblasts are mesenchymal cells derived from mesodermal and neural crest progenitor cells and their formation entails differentiation from progenitors into proliferating preosteoblasts, bone matrix-producing osteoblasts, and eventually into osteocytes or a bone-lining cells. The earliest osteoblastic marker, Runt-related transcription factor 2 (Runx2) is necessary for progenitor cell differentiation along the osteoblast lineage [9]. During this sequence of cellular proliferation Runx2 regulates expression of genes encoding osteocalcin, VEGF, RANKL, sclerostin, and dentin matrix protein 1 [DMP1] [10]. Osterix is another transcription factor essential for osteoblast differentiation [11]. A large number of paracrine, autocrine, and endocrine factors affect osteoblast development and maturation like: bone morphogenetic proteins (BMPs), growth factors like FGF and IGF, angiogenic factors like endothelin-1, hormones like PTH and prostaglandin agonists, all modulate osteoblast differentiation [12]. The action of PTH and BMPs is closely associated with activation of Wnt signalling pathways [13].

The fully differentiated osteoblast is characterized by coexpression of alkaline phosphatase and type I collagen, both important for synthesis of bone matrix and subsequent mineralization thereof [14]. Mature osteoblasts also produce regulators of matrix mineralization like osteocalcin, osteopontin and ostenectin, RANKL which is necessary for osteoclast differentiation as well as the receptor for PTH (PTHR1). At the end of their lifespan osteoblasts transform into either osteocytes which become embedded in the mineralized matrix or lining cells, which cover all surfaces of bone. Specific molecules expressed by osteocytes include DMP1, FGF 23 and 
sclerostin, which control bone formation and phosphate metabolism [15].

\subsubsection{Wnts and osteoblast differentiation}

Wnts are secreted glycoproteins crucial for the development and renewal of many tissues, including bone. Wnt signalling dominate osteoblast differentiation pathways and act via binding to a receptor complex consisting of LDL receptor-related protein 5 (LRP5) orLRP6 and one of ten Frizzled molecules [13]. The so called canonical Wnt signaling pathway is active in all cells of the osteoblastic lineage, and involves the stabilization of $\beta$-catenin and regulation of multiple transcription factors [16]. Wnt $/ \beta$ catenin signaling is also important for mechanotransduction, fracture healing and osteoclast maturation [17-19].

The activation of canonical Wnt-signaling promotes osteoblast differentiation from mesenchymal progenitors at the expense of adipogenesis, which leads to improved bone strength, while suppression causes bone loss [20]. Canonical Wnt signaling in osteoblast differentiation is modulated by Runx2 and osterix [21].

Wnt signaling is a prime target for bone active drugs and the approaches include inhibition of Wnt antagonist like Dkk1, sclerostin, and Sfrp1 with neutralizing antibodies and inhibition of glycogen synthase kinase $3 \beta$ (GSK3 $\beta$ ), which promotes phosphorylation and degradation of $\beta$ catenin. One of the most promising approaches so far has been inhibition of the osteocyte protein sclerostin, which exerts tonic inhibition of osteoblast activity [22]. Sclerostin is the product of the SOST gene, which is mutated and downregulated in patients with sclerosteosis and van Buchem disease and sclerosteosis [23], which are diseases characterized by high bone density. Expression levels of sclerostin are repressed in response to mechanical loading and intermittent PTH treatment [24]. Preliminary studies with a humanized monoclonal antibody against sclerostin have shown bone anabolism in animals as well as humans [25].

\subsection{Osteoclast differentiation}

The dominating pathway regulating osteoclast differentiation is the RANKL/RANK/OPG pathway. This pathway is based on osteoblasts promoting osteoclast differentiation through membrane presentation of RANKL and binding of this factor to the membrane receptor RANK on mononuclear osteoclast precursors. Osteoclast differentiation is also modulated by M-CSF [26]. The promotion of osteoclast differentiation by RANKL is inhibited by the decoy receptor osteoprotegerin (OPG), which is also produced by osteoblasts [26] (74). Estrogens increase OPG and decrease RANKL expression in osteblasts, thus favoring bone formation. Postmenopausal bone loss is linked to reduced estrogen levels favoring increased resorption. In many instances [26]. PTH given as daily injections favors bone anabolism, reduces RANKL and increases OPG levels. In cases with chronic elevation of circulating PTH levels as seen in primary hyperparathyroidism the opposite pattern is seen with elevated RANKL and reduced OPG levels. A humanized monoclonal antibody against RANKL has been shown to elicit even more pronounced reduction in osteoclast numbers [27] than bisphosphonates and has demonstrated excellent reduction of fracture risk in postmenopausal osteoporosis [28].

\subsection{Coupling between resorption and formation}

During normal bone remodeling, the amount of resorbed bone is completely replaced in location and amount by new bone. This is secured through tight coupling of bone resorption to bone formation. The mechanisms underlying the coupling process still remains largely elusive, although the last 15 years has increased our knowledge significantly.

The dominating hypothesis years ago was that liberation of growth factors like IGF 1 and 2 and cytokines embedded in bone matrix during bone resorption secured the balance between resorption and formation during bone remodeling [29]. Later work showing that osteoblastic bone formation proceeds unperturbed despite lack of bone resorption in the presence of defective osteoclasts lacking for example chloride channels or important factors for ruffled border formation in osteoclasts like c-Src [30] has supplemented this hypothesis. The important role that osteoclasts play in the regulation of bone formation is also corroborated by studies on mice lacking c-fos or M-CSF, which display absence of osteoclasts and defective bone formation [31].

Other system involved in coupling of bone resorption to bone formation are the transmembrane proteins, ephrinB2, which are expressed on osteoblasts and EPH receptor B4 (EphB4), which are expressed on osteoclasts [32]. Also the osteoclastic factor sphingosine 1-phosphate (S1P) [33] seems to play a significant role. The interaction of Ephrin and EPH by cell to cell contact promotes osteoblast differentiation and represses osteoclast differentiation. Secretion of S1P by osteoclast seems to recruit osteoblast progenitor cells to sites of bone resorption and stimulate differentiation of these progenitor cells by stimulating EphB4 signaling, This causes a shut down of bone resorption and initiate the formative phase of bone remodeling in the so called transition phase.

\section{Targeted and non-targeted remodeling}

Through its constant removal and renewal of damaged bone, bone remodeling secures skeletal integrity throughout 
life. It has become customary to distinguish between targeted and non-targeted (stochastic) remodeling. Nontargeted remodeling denotes regulation remodeling by hormones like PTH, thyroxine, growth hormone and estrogen, but also antiresorptive drugs like bisphosphonates may affect non-targeted remodeling. It seems that the main pathway is via modulation of osteoclasts, which then via the coupling between resorption and formation subsequently affects osteoblast activity. Targeted remodeling secures removal of damaged bone through targeted resorption. Osteocytes are the most abundant cells in bone, and their death by microdamage has been suggested to be the major event leading in the initiation of osteoclastic bone resorption. In normal bone [34]. Resorption lacunae are 3 times more frequent in association with microcracks, indicating that remodeling is associated with repair of such microdamage [35]. Damaged osteocytes promote differentiation of osteoclast precursors driven by secretion of M-CSF and RANKL [36]. In cortical bone there is evidence to suggest, that microdamage not only activates new BMUs, but may also may direct the movement of existing BMUs as they tunnel through the cortex. It also seems that the degree of damage to the osteocyte network determines osteocyte metabolic responses to loading and influences targeted remodeling [37].

Analysis of the relationship of between mean microcrack length and BMU resorption space density in cortical bone indicates that BMUs have an effective area about 40 times greater than their actual cross-section, which suggests that osteoclasts in the cutting cone of cortical BMUs are able to sense and steer toward microdamage [38]. The relation between microdamage and initiation of bone remodeling is further corroborated by the fact that osteoclastic resorption is augmented in old bone [39].

\section{The bone remodeling compartment}

The work by Hauge et al. [40] demonstrated that the cells in the BMU, even in cancellous bone, were not directly contiguous to the bone marrow, but rather they were covered by a "canopy" of cells forming the outer lining of a specialized vascular structure with the denuded bone surface as the other delineation. The cells of this canopy display all classicial markers of the osteoblastic phenotype (Table 1), and are therefore most probably bone-lining cells, which seem to be connected to bone-lining cells on the quiescent bone surface. The structure has been demonstrated in cortical as well as cortical bone (Fig. 2). In turn, these bone-lining cells on the quiescent bone surface are in communication with osteocytes embedded within the bone matrix. Penetrating the canopy of bone-lining cells, and presumably serving as a conduit for the cells needed in the $\mathrm{BMU}$, are capillaries.
Table 1 Osteoblastic and endothelial markers detected on cells lining the Bone remodeling Compartment (BRC) vs. vascular endothelial cells as assessed by immuno- and enzyme histochemical staining

\begin{tabular}{lll}
\hline Antigen & BRC & Vascular endothelium \\
\hline VEGF & - & + \\
Von Willebrand Factor & - & + \\
CD 34 & - & + \\
Alkaline Phosphatase* & + & - \\
Osteocalcin & + & - \\
Osteonectin & + & - \\
IGF 1,2 & + & - \\
TGF $\beta$ 1,2,3 & + & - \\
bFGF & + & - \\
OPG & + & - \\
RANKL & + & - \\
\hline
\end{tabular}
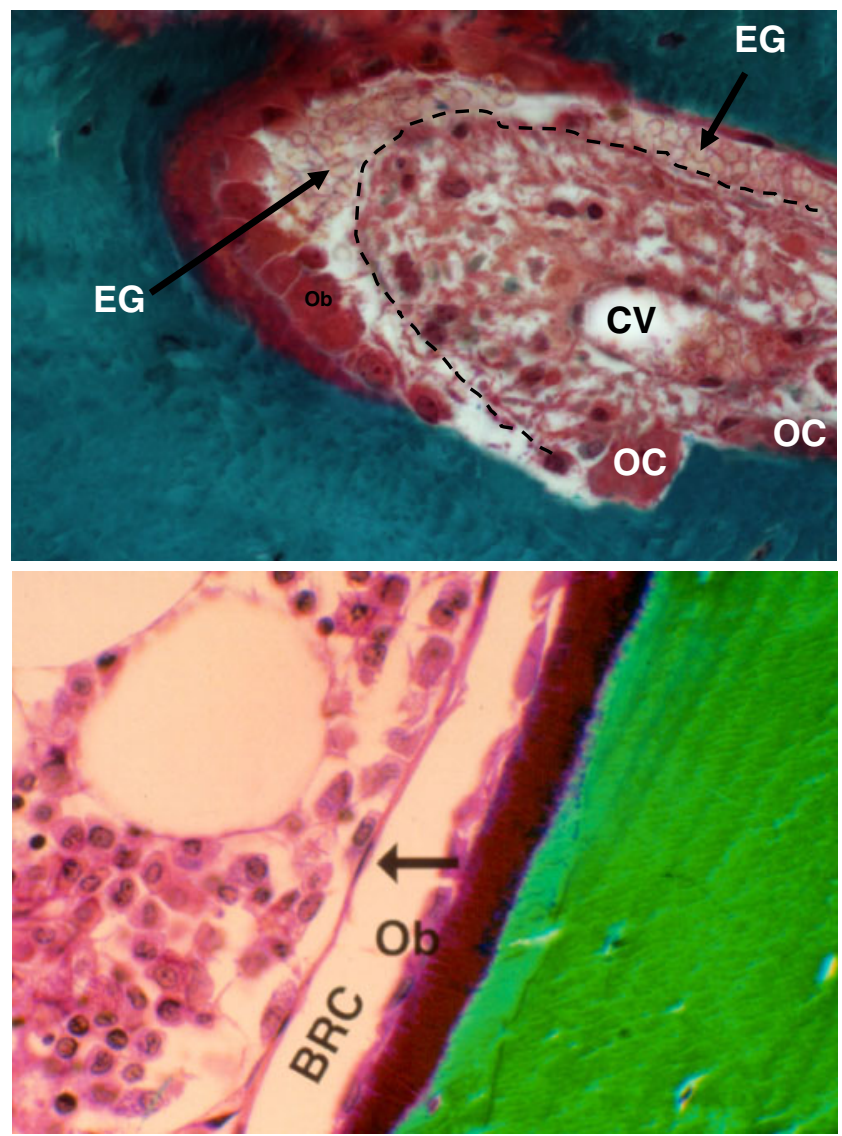

Fig. 2 Different representations of BRC structures in cortical (upper panel) and trabecular bone (lower panel). In cortical bone the BRC (outer demarcation by the broken line) is filled with erythrocyte ghosts (EG) and is located at the closing cone of the Haversian system situated over osteoblasts (OB). A few osteoclasts (OC) are also seen. $\mathrm{CV}$ denotes the central vessel of the Haversian system. In trabecular bone (lower panel) the outer lining of the BRC is clearly discernible, demarcating a vascular structure on top of osteoblasts (OB). Picture in upper panel courtesy of Pierre Delmas, Lyon, France 
Angiogenesis is closely associated with bone resorption and bone and angiogenic factors like VEGF and endothelin regulate osteoclast and osteoblast activity [41]. In addition blood vessels serve as a way of transporting circulating osteoblast [42] and osteoclast precursors [43] to sites undergoing active remodeling. The involvement of vascular cells during the initiation of bone resorption is still unresolved. Is the very first step adhesion of a blood vessel to bone lining cells at a site where targeted repair is needed? Conceivably, osteocyte apoptosis and possible release of osteotropic growth factors and cytokines could be attractants for blood vessels, which would then subsequently initiate the formation of a resorptive BRC. But, as outlined above, the framework for signaling within the osteocyte-lining cell-BRC network could also be a way by which remodeling events on bony surfaces are triggered from damage accumulation or changes in mechanical strain within bone.

There is increasing evidence for a common lineage and close interaction between vascular endothelial cells and bone cells. Endothelial cells drive differentiation of marrow stromal cell towards the osteoblastic phenotype [44] Endothelin and VEGF are also involved in signaling between vasculature and bone [45], and VEGF as well as other angiogenic factors are expressed during intramembranous osteogenesis. Osteoblastic cells, as well as osteoclasts, possess receptors for VEGF and also produce VEGF [46]. Expression of VEGF is closely associated with the early phases of bone modeling and remodeling events [47] and it induces osteoblast chemotaxis and differentiation [48] and differentiation.

Cells may enter the remodeling space either via diapedesis through the lining cell dome covering the BRC or via the circulation. It is still debatable whether all cells involved in remodeling arrive via the circulation, but while circulating osteoclast precursors were demonstrated more than a decade ago, there is now increasing evidence that osteoblast lineage cells are also present in the circulation strengthening the involvement of circulating precursor cells in the process $[42,49,50]$.

While the systemic hormonal regulation of the remodeling process has to occur via factors arriving at individual remodeling sites via the bloodstream, the way by which local regulatory factors exert their action on individual cell populations involved is still obscure. Over the last decades, however, we have increased our knowledge about the different growth factors and cytokines involved in local regulation of bone remodeling tremendously (Fig. 3). Apart from growth factors and cytokines, simple molecules like nitrogen oxide (NO), as well as hypoxia and acidosis have been shown to exert pronounced effects on bone remodeling balance and activity. NO exerts biphasic effects on osteoclast activity with low concentrations potentiating and high concentrations inhibiting bone resorption [51]. Similarly, osteoblastic growth and differentiation are inhibited by high concentrations of NO, while lower concentrations may play a role in regulating normal osteoblast growth and in mediating the effects of estrogens on bone formation, mechanotransduction and bone anabolic responses [51]. The dominating isoform of nitrogen oxide synthase (eNOS) is expressed in osteocytes and lining cells, but not in cuboidal osteoblasts [52]. Acidosis and hypoxia generally increase bone resorption [53-56] and inhibit bone formation [57]. As hypoxia may cause acidosis through increased anaerobic metabolism, the two factors may act synergistically at the tissue level [56]. Hypoxia and acidosis also affect secretion of pro-angiogenic factors like VEGF as outlined below.

\section{Key functions of the bone remodeling compartment}

1. The BRC provides a closed microenvironment permitting tight regulation of bone remodeling. Current concepts regarding local regulation of bone remodeling generally assumes that the local growth factors, cytokines and even $\mathrm{NO}$ come either from cells in the marrow space or vascular cells having free access to the remodeling site without barriers, or are produced by osteoclasts and osteoblasts at the remodeling site. The BRC concept implies that the all factors liberated from the cells or vessels in the marrow space exert their regulatory role either through diffusion through the outer layer of the BRC, transport via the bloodstream to the interior of the BRC or indirectly via modulation of cell activity in the outer wall of the BRC. The presence of a specific compartment in which remodeling can proceed without interference from local factors liberated in the marrow space seems to be logical. If the access to the marrow space was open, the very high levels of growth factors in the marrow microenvironment might offset eventual localized regulatory effects by local growth factors, crucial to osteoclast and osteoblast differentiation and the remodeling process.

2. The BRC is the structure translating microdamage into targeted remodeling by which mechanosensory signals from the osteocyte network are translated into changes in osteoclast and osteoblast activity on trabecular surfaces. Lining cells are connected to the osteocyte network via gap junctions between lining cells on quiescent surfaces and osteocyte cannaliculi [58] (Fig. 4). Signals from lining cells indicating damage or stress could be transmitted to the outer lining cell layer of the BRC and trigger osteoclast recruitment. By analogy with remodeling in cortical bone, which is clearly associated with growth of a blood vessel into 


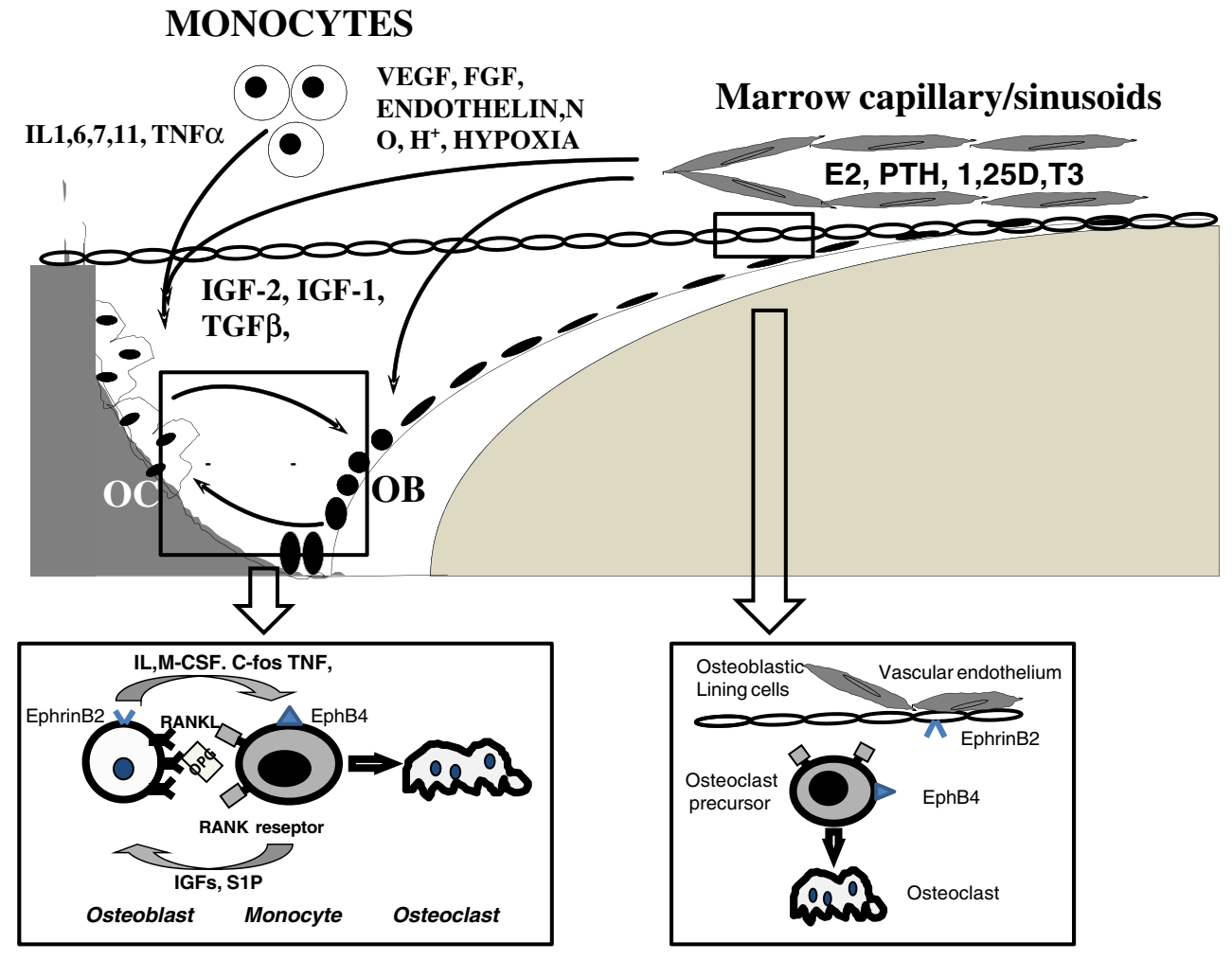

Fig. 3 Depiction of some of the main local regulatory factors operating at remodeling sites with osteoclasts (OC) and osteoblasts (OB). Interleukins (IL), tumor necrosis factors (TNF), transforming growth factors (TGF), colony stimulating factors (CSF), Insulin like growth factors (IGF), fibroblast growth factors (FGF), platelet derived growth factors (PDGF), bone morphogenetic proteins (BMP)) are formed by both monocytic cells in the marrow space or circulation, as well as bone cells in the BMU. NFKB- or RANK- ligand (RANKL) and osteoprotegerin (OPG) are formed specifically by osteoblasts. Factors from the marrow space as well as factors liberated by

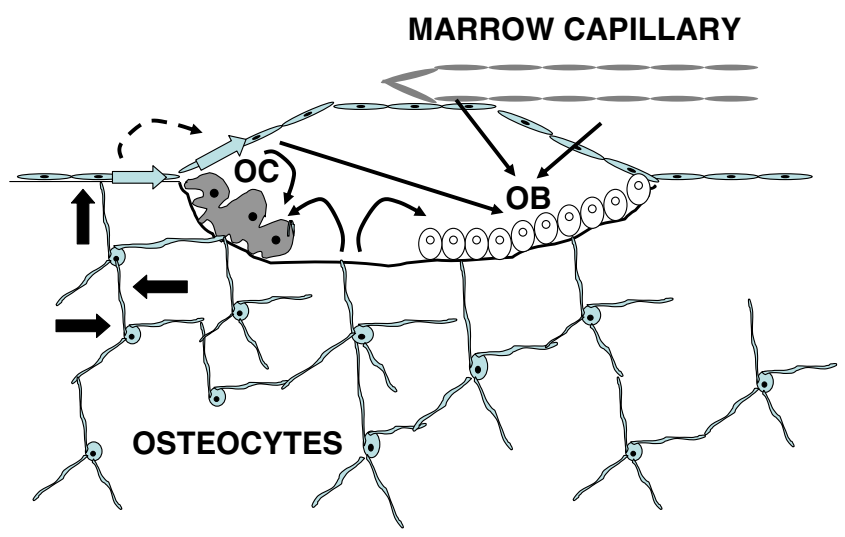

Fig. 4 Connections between the osteocyte network, lining cells and the BRC. All cells in this network are connected with gap junctions, which may provide a pathway (block arrows), by which signals generated deep within bone may reach the surface and elicit remodeling events by osteoclasts (OC) and osteoblasts (OB) in response to mechanical stimuli. The response may be modulated by factors liberated from the vascular endothelium or marrow capillaries/sinusoids and paracrine factors (broken arrow) liberated from lining cells may also play a role

endothelial cells (vascular endothelial growth factor (VEGF), endothelin, nitrogen oxide (NO)) may diffuse to receptors on osteoclasts or osteoblasts. The cellular responses in the BMU are then further modulated by systemic hormones in the circulation (estrogen (E2), parathyroid hormone $(\mathrm{PTH})$, active vitamin D $(1,25 \mathrm{D})$, thyroid hormone (T3)). Left lower insert depicts in detail osteoblastosteoclast interactions inside the BRC and right lower insert depict an alternativ, still hypohetical, version of that interaction based on lining cells acting as the osteoblastic component in thata interaction

the remodeling site (5), the presumed ingrowth of a capillary into the BRC provides the vascular supply for the cells in the BMU of cancellous bone and might also provide the necessary osteoclasts and, subsequently, the osteoblasts that are needed for bone remodeling in both cancellous and cortical bone The BRC would also be a site where hormonal modulation (e.g. ERT) of the mechanosensory input could take place [59].

3. The BRC is the most probable structure at which coupling between osteoclasts and osteoblasts occurs. The RANKL/OPG pathway involves presentation of osteoblastic, membrane bound RANKL to the RANK receptor on osteoclast precursors by cell to cell contact. Due to the timing and sequence of bone resorption and bone formation, however, resorption and formation are generally separated in time and space, which makes the needed cell to cell contact between osteoclast precursors and active osteoblasts highly unlikely on a broader basis, and even if soluble RANKL played a major role it had no RANKL on precursor cells within the BRC to 
bind to. A more likely cell, which could present RANKL to RANK on osteoclast precursors, would be the lining cell. As demonstrated in animals [60] and in humans [61], lining cells exhibit positive immunoreactivity for OPG and RANKL, and might therefore be responsible for the cell to cell contact with osteoclast precursors.

4. The BRC also obviates the need for a "postal code" system ensuring that resorptive and formative cells adhere to areas on the bone surface, where they are needed. Bone surfaces are generally covered by lining cells, which would prevent direct contact between bone cells and integrins or other adhesion molecules known to modulate cell activity. The BRC would be the only place where these cells (circulating osteoclasts as well as circulating osteoblast precursors) would be exposed to these matrix constituents, because the formation of the BRC involves detachment of lining cells from the bone surface.

5. The BRC may play a crucial role in the spread of bone metastases. It is well established that apart from entering bone via local ingrowth, tumor cells reach bony surfaces via the circulation. The growth of metastatic cells in bone is enhanced by the so called "vicious cycle", where PTHrp produced by tumor cells (e.g. breast cancer cells) induces increased local bone resorption and subsequent liberation of TGF $\beta$ from the bone matrix [62]. The local effects of TGF $\beta$ in the bone microenvironment are two-fold: 1) it enhances the growth of bone metastases and 2) increases PTHrp formation from tumor cells further [62], thus maintaining the vicious cycle. As shown above, one of the key components of the vicious cycle, TGF $\beta$, is produced by the cells lining the BRC. Other key promoters of bone metastases like IL- 1 and IL- 6 are also produced by the lining cell layer covering BRCs. It is therefore probable that the microenvironment in the BRC is highly conducive to metastatic seeding and the formation of the vicious cycle, further enabling growth of the bone metastasis. Moreover, the existence of a closed compartment would make vicious cycle formation easier due to absence of interference with cytokine and growth factors from the marrow space. Several large scale studies have established that bisphosphonates reduce the number of skeletal events in breast cancer, prostate cancer and myelomatosis, and iv bisphosphonates are now used routinely in advanced cancer [63]. There is still debate as to how much of the beneficial effects of bisphosphonates in advanced cancer are due to inhibition of angiogenesis or to other, direct antitumor effects. Bisphosphonate, however, could exert their inhibitory effects on bone metastases simply by reducing the number of BRCs and thereby the surface of denuded bone available for metastatic seeding.

\section{Conclusion}

Bone remodeling involves tight coupling and regulation of osteoclasts and osteoblasts and is modulated by a wide variety of hormones and osteocyte products secreted in response to mechanical stimulation and microdamage. Bone remodeling proceeds in a specialized vascular entity the "Bone Remodeling Compartment" (BRC), which provides the structural basis for coupling and regulation of cellular activity. Increased knowledge about the interplay between different factors and cells surrounding the BRC will most likely result in even better treatment options for skeletal disease.

Open Access This article is distributed under the terms of the Creative Commons Attribution Noncommercial License which permits any noncommercial use, distribution, and reproduction in any medium, provided the original author(s) and source are credited.

\section{References}

1. Frost HM. Tetracycline-based histological analysis of bone remodeling. Calcif Tissue Res. 1969;3:211-37.

2. Eriksen EF. Normal and pathological remodeling of human trabecular bone: three dimensional reconstruction of the remodeling sequence in normals and in metabolic bone disease. Endocr Rev. 1986;7:379-408.

3. Eriksen EF, Gundersen HJ, Melsen F, Mosekilde L. Reconstruction of the formative site in iliac trabecular bone in 20 normal individuals employing a kinetic model for matrix and mineral apposition. Metab Bone Dis Relat Res. 1984;5:243-52.

4. Eriksen EF, Melsen F, Mosekilde L. Reconstruction of the resorptive site in iliac trabecular bone: a kinetic model for bone resorption in 20 normal individuals. Metab Bone Dis Relat Res. 1984;5:235-42.

5. Eriksen EF, Hodgson SF, Eastell R, Cedel SL, O'Fallon WM, Riggs BL. Cancellous bone remodeling in type I (postmenopausal) osteoporosis: quantitative assessment of rates of formation, resorption, and bone loss at tissue and cellular levels. J Bone Miner Res. 1990;5:311-9.

6. Agerbaek MO, Eriksen EF, Kragstrup J, Mosekilde L, Melsen F. A reconstruction of the remodelling cycle in normal human cortical iliac bone. Bone Miner. 1991;12:101-12.

7. Parfitt AM. The mechanism of coupling: a role for the vasculature. Bone. 2000;26:319-23.

8. Burkhardt R. In: Arlet J, Ficat RP, Hungerford DS, editors. The structural relationship of bone forming and endothelial cells of the bone marrow. Baltimore: Williams \& Wilkins; 1984. p. 2-14.

9. Komori T, Yagi H, Nomura S, Yamaguchi A, Sasaki K, Deguchi K, et al. Targeted disruption of Cbfa1 results in a complete lack of bone formation owing to maturational arrest of osteoblasts. Cell. 1997;89:755-64.

10. Lian JB, Stein GS, Javed A, van Wijnen AJ, Stein JL, Montecino M, et al. Networks and hubs for the transcriptional control of osteoblastogenesis. Rev Endocr Metab Disord. 2006;7:1-16.

11. Nakashima K, Zhou X, Kunkel G, Zhang Z, Deng JM, Behringer $\mathrm{RR}$, et al. The novel zinc finger-containing transcription factor osterix is required for osteoblast differentiation and bone formation. Cell. 2002;108:17-29. 
12. Qin L, Qiu P, Wang L, Li X, Swarthout JT, Soteropoulos P, et al. Gene expression profiles and transcription factors involved in parathyroid hormone signaling in osteoblasts revealed by microarray and bioinformatics. J Biol Chem. 2003;278:1972331.

13. Westendorf JJ, Kahler RA, Schroeder TM. Wnt signaling in osteoblasts and bone diseases. Gene. 2004;341:19-39.

14. Murshed M, Harmey D, Millan JL, McKee MD, Karsenty G. Unique coexpression in osteoblasts of broadly expressed genes accounts for the spatial restriction of ECM mineralization to bone. Genes Dev. 2005;19:1093-104.

15. Bonewald L. Osteocytes as multifunctional cells. J Musculoskelet Neuronal Interact. 2006;6:331-3.

16. Hens JR, Wilson KM, Dann P, Chen X, Horowitz MC, Wysolmerski JJ. TOPGAL mice show that the canonical Wnt signaling pathway is active during bone development and growth and is activated by mechanical loading in vitro. J Bone Miner Res. 2005;20:1103-13.

17. Robinson JA, Chatterjee-Kishore M, Yaworsky PJ, Cullen DM, Zhao $\mathrm{W}$, Li $\mathrm{C}$, et al. Wnt/beta-catenin signaling is a normal physiological response to mechanical loading in bone. J Biol Chem. 2006;281:31720-8.

18. Chen Y, Whetstone HC, Lin AC, Nadesan P, Wei Q, Poon R, et al. Beta-catenin signaling plays a disparate role in different phases of fracture repair: implications for therapy to improve bone healing. PLoS Med. 2007;4:e249.

19. Spencer GJ, Utting JC, Etheridge SL, Arnett TR, Genever PG. Wnt signalling in osteoblasts regulates expression of the receptor activator of NFkappaB ligand and inhibits osteoclastogenesis in vitro. J Cell Sci. 2006;119:1283-96.

20. Bodine PV, Komm BS. Wnt signaling and osteoblastogenesis. Rev Endocr Metab Disord. 2006;7:33-9.

21. Hill TP, Spater D, Taketo MM, Birchmeier W, Hartmann C. Canonical Wnt/beta-catenin signaling prevents osteoblasts from differentiating into chondrocytes. Dev Cell. 2005;8:727-38.

22. van Bezooijen RL, Svensson JP, Eefting D, Visser A, van der Horst G, Karperien M, et al. Wnt but not BMP signaling is involved in the inhibitory action of sclerostin on BMP-stimulated bone formation. J Bone Miner Res. 2007;22:19-28.

23. Balemans W, Ebeling M, Patel N, Van HE, Olson P, Dioszegi M, et al. Increased bone density in sclerosteosis is due to the deficiency of a novel secreted protein (SOST). Hum Mol Genet. 2001;10:537-43.

24. Keller H, Kneissel M. SOST is a target gene for PTH in bone. Bone. 2005;37:148-58.

25. Padhi D, Jang G, Stouch B, Fang L, Posvar E. Single-dose, placebo-controlled, randomized study of AMG 785, a sclerostin monoclonal antibody. J Bone Miner Res. 2010.

26. Khosla S. Minireview: the OPG/RANKL/RANK system. Endocrinology. 2001;142:5050-5.

27. Reid IR, Miller PD, Brown JP, Kendler DL, Fahrleitner-Pammer A, Valter I, et al. Effects of denosumab on bone histomorphometry: the FREEDOM and STAND studies. J Bone Miner Res. 2010;25:2256-65.

28. Cummings SR, San MJ, McClung MR, Siris ES, Eastell R, Reid IR, et al. Denosumab for prevention of fractures in postmenopausal women with osteoporosis. N Engl J Med. 2009;361:75665.

29. Mohan S, Baylink DJ. Insulin-like growth factor system components and the coupling of bone formation to resorption. Horm Res. 1996;45 Suppl 1:59-62.

30. Karsdal MA, Martin TJ, Bollerslev J, Christiansen C, Henriksen $\mathrm{K}$. Are nonresorbing osteoclasts sources of bone anabolic activity? J Bone Miner Res. 2007;22:487-94.

31. Dai XM, Zong XH, Akhter MP, Stanley ER. Osteoclast deficiency results in disorganized matrix, reduced mineralization, and abnormal osteoblast behavior in developing bone. J Bone Miner Res. 2004;19:1441-51.

32. Zhao C, Irie N, Takada Y, Shimoda K, Miyamoto T, Nishiwaki T, et al. Bidirectional ephrinB2-EphB4 signaling controls bone homeostasis. Cell Metab. 2006;4:111-21.

33. Ryu J, Kim HJ, Chang EJ, Huang H, Banno Y, Kim HH. Sphingosine 1-phosphate as a regulator of osteoclast differentiation and osteoclast-osteoblast coupling. EMBO J. 2006;25:584051.

34. Cardoso L, Herman BC, Verborgt O, Laudier D, Majeska RJ, Schaffler MB. Osteocyte apoptosis controls activation of intracortical resorption in response to bone fatigue. J Bone Miner Res. 2009;24:597-605.

35. Li J, Mashiba T, Burr DB. Bisphosphonate treatment suppresses not only stochastic remodeling but also the targeted repair of microdamage. Calcif Tissue Int. 2001;69:281-6.

36. Kurata K, Heino TJ, Higaki H, Vaananen HK. Bone marrow cell differentiation induced by mechanically damaged osteocytes in 3D gel-embedded culture. J Bone Miner Res. 2006;21:616-25.

37. Colopy SA, Benz-Dean J, Barrett JG, Sample SJ, Lu Y, Danova NA, et al. Response of the osteocyte syncytium adjacent to and distant from linear microcracks during adaptation to cyclic fatigue loading. Bone. 2004;35:881-91.

38. Burger EH, Klein-Nulend J, Smit TH. Strain-derived canalicular fluid flow regulates osteoclast activity in a remodelling osteon-a proposal. J Biomech. 2003;36:1453-9.

39. Henriksen K, Leeming DJ, Byrjalsen I, Nielsen RH, Sorensen MG, Dziegiel MH, et al. Osteoclasts prefer aged bone. Osteoporos Int. 2007;18:751-9.

40. Hauge EM, Qvesel D, Eriksen EF, Mosekilde L, Melsen F. Cancellous bone remodeling occurs in specialized compartments lined by cells expressing osteoblastic markers. J Bone Miner Res. 2001;16:1575-82.

41. Brandi ML, Collin-Osdoby P. Vascular biology and the skeleton. J Bone Miner Res. 2006;21:183-92.

42. Eghbali-Fatourechi GZ, Lamsam J, Fraser D, Nagel D, Riggs BL, Khosla S. Circulating osteoblast-lineage cells in humans.[see comment]. N Engl J Med. 2005;352:1959-66.

43. Kassem M, Risteli L, Mosekilde L, Melsen F, Eriksen EF. Formation of osteoblast-like cells from human mononuclear bone marrow cultures. APMIS. 1991;99:269-74.

44. Kaigler D, Krebsbach PH, Polverini PJ, Mooney DJ. Role of vascular endothelial growth factor in bone marrow stromal cell modulation of endothelial cells. Tissue Eng. 2003;9:95-103.

45. Veillette CJ, von Schroeder HP. Endothelin-1 down-regulates the expression of vascular endothelial growth factor-A associated with osteoprogenitor proliferation and differentiation. Bone. 2004;34:28896.

46. Tombran-Tink J, Barnstable CJ. Osteoblasts and osteoclasts express PEDF, VEGF-A isoforms, and VEGF receptors: possible mediators of angiogenesis and matrix remodeling in the bone. Biochem Biophys Res Commun. 2004;316:573-9.

47. Xiong $\mathrm{H}$, Rabie AB. Neovascularization and mandibular condylar bone remodeling in adult rats under mechanical strain. Front Biosci. 2005;10:74-82.

48. Li G, Cui Y, McIlmurray L, Allen WE, Wang H. rhBMP-2, rhVEGF(165), rhPTN and thrombin-related peptide, TP508 induce chemotaxis of human osteoblasts and microvascular endothelial cells. J Orthop Res. 2005;23:680-5.

49. Zvaifler NJ, Marinova-Mutafchieva L, Adams G, Edwards CJ, Moss J, Burger JA, et al. Mesenchymal precursor cells in the blood of normal individuals. Arthritis Res. 2000;2:477-88.

50. Kuznetsov SA, Mankani MH, Gronthos S, Satomura K, Bianco P, Robey PG. Circulating skeletal stem cells. J Cell Biol. 2001;153:1133-40. 
51. Ralston SH, Ho LP, Helfrich MH, Grabowski PS, Johnston PW, Benjamin N. Nitric oxide: a cytokine-induced regulator of bone resorption. J Bone Miner Res. 1995;10:1040-9.

52. Fox SW, Chow JW. Nitric oxide synthase expression in bone cells. Bone. 1998;23:1-6.

53. Bushinsky DA. Acid-base imbalance and the skeleton [Review] [67 refs]. Eur J Nutr. 2001;40:238-44.

54. Goldhaber P, Rabadjija L. H+ stimulation of cell-mediated bone resorption in tissue culture. Am J Physiol. 1987;253:E90-8.

55. Arnett TR, Dempster DW. Effect of $\mathrm{pH}$ on bone resorption by rat osteoclasts in vitro. Endocrinology. 1986;119:119-24.

56. Arnett TR, Gibbons DC, Utting JC, Orriss IR, Hoebertz A, Rosendaal M, et al. Hypoxia is a major stimulator of osteoclast formation and bone resorption. J Cell Physiol. 2003;196:2-8.

57. Utting JC, Robins SP, Brandao-Burch A, Oriss IR, Behar J, Arnett TR. Hypoxia inhibits the growth, differentiation and bone forming capacity of rat osteoblasts. Exp Cell Res. 2006;312:1694-702.
58. Marotti G, Ferretti M, Muglia MA, Palumbo C, Palazzini S. A quantitative evaluation of osteoblast-osteocyte relationships on growing endosteal surface of rabbit tibiae. Bone. 1992;13:363-8.

59. Bonewald LF. Osteocyte biology: its implications for osteoporosis. J Musculoskelet Neuronal Interact. 2004;4:101-4.

60. Silvestrini G, Ballanti P, Patacchioli F, Leopizzi M, Gualteri N, Monnazzi P, et al. Detection of osteoprotegerin (OPG) and its ligand (RANKL) mRNA and protein in femur and tibia of the rat. J Mol Histol. 2005;36:59-67.

61. Eriksen EF, Qvesel D, Hauge EM, Melsen F. Further evidence that vascular remodeling spaces are lined by cells of osteogenic origin: characterization of a possible coupling structure. J Bone Miner Res. 2005;15:S371.

62. Mundy GR. Mechanisms of bone metastasis [Review] [99 refs]. Cancer. 1997;80:1546-56.

63. Polascik TJ. Bisphosphonates in oncology: evidence for the prevention of skeletal events in patients with bone metastases. Drug Des Devel Ther. 2009;3:27-40. 